\title{
14 In and out of place
}

\author{
Lia Bryant
}

\section{Introduction}

She stares at yellow fields of wheat flicking past her. The long stretch of road ahead. Feeling the rhythm and dip of the car as she manoeuvres around corners, she notices the size and shape of trees dotted along the open spaces. She holds a conversation with herself; it's almost a game identifying crops by their growth and color (Figure 14.1).

For a qualitative researcher like me, rural research is very much emplaced and sensory. COVID-19 physically removes me from the communities and rural people I partner with and I am increasingly on my mobile phone. On days when the Internet is good (it often isn't in rural Australia), I am on Zoom. My work now involves sitting in my home office in suburban Adelaide, South Australia. I now listen carefully to voices. However, so much of what I have learned about rurality and gender emerged from being in place and, a lot of the time, it's from being there but feeling out of place.

Paradoxically, it is in the city where I have often reflected back on rural places using memory work, an auto-ethnographic method which involves the writing of a memory in the third person on an encounter, emotion, or theme. As memory work enables me to be reflexive about my practice it made sense while being physically away from the rural to use this method for writing this piece (see Bryant and Livholts, 2007, 2015).

\section{Out of place: matter that matters}

I enjoy thinking about how the spaces I enter hold histories and take shape materially in bricks and mortar. I am curious about how spaces come alive through language but also through our senses as people enter a local grocery shop in a rural town, a farm house, a shearing shed, and paddocks. Particularly, I am interested in how we affect one another and how we are 


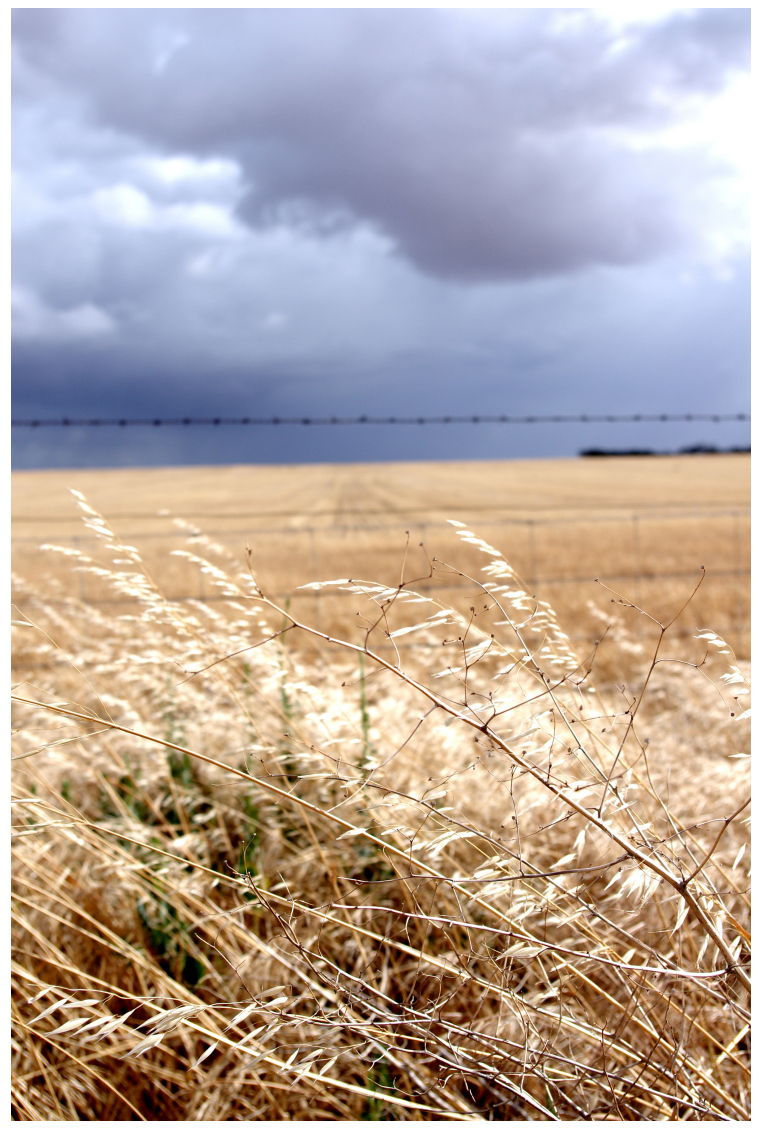

Figure 14.1 Wheat (Lia Bryant).

affected by objects, landscapes, insects, elements, and animals. These entangled affective relationships have occupied social scholarship for some time and feminist theorists (Butler, 1993; Haraway, 1988, 2008; Barad, 2003) have brought attention to a focus on women's bodies in relation to "things."

Hence, I dedicated a chapter, "Sites/sights of exclusion," in my book Water and Rural Communities to the colonial structure of the water-governance building. I bring attention to the white masculinised board room where large heavy portraits of chairmen of the board hang (Bryant and George, 2016). In the board room, the power of "things" becomes apparent - a table, chairs, portraits of men, and cabinets of tools many of which are unknown to me. This building is not simply a representation of the past. It is matter 


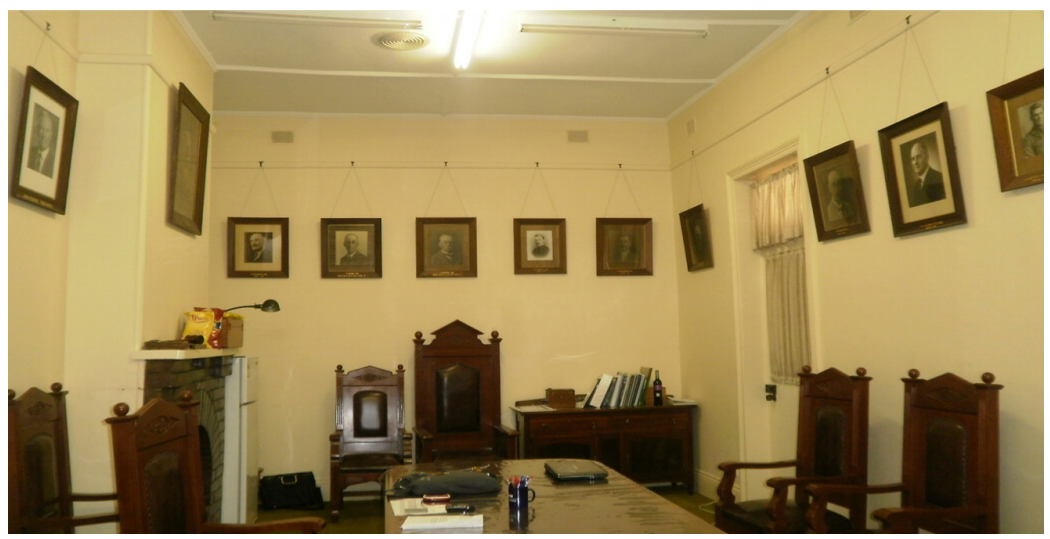

Figure 14.2 The Boardroom of the Water Trust (Lia Bryant).

that matters. The textures of the Water Trust's built environment are "felt materially and atmospheric attunements are palpable and sensory" (Tolia Kelly, 2011:157, citing Stewart, 2011:446). This living space (Jacobs, 2006) endorses a political praxis of welcoming some bodies over others (Figure 14.2).

I have a vivid memory of my first visit to the Trust: I was ushered in to sit in high dark wooden chairs along a table that was equally heavy and ornate. I remember thinking this room was reminiscent of a dining hall in an English castle. The furniture was obviously imported when the town was settled - erasing the presence of Indigenous Australians and the waves of non-British migration since 1950. I noted the sensations of discomfort growing as my body was forced upright in this formal setting. It was hard to make eye contact with the men who sat up and down the length of the table. I came to talk about gender and water governance during drought.

At one point in the discussion I asked, "Are there women on the board of the Water Trust?"

I was met with throaty laughter. "In our 120 years, we haven't had a woman on the board."

My body in this space was foreign and I felt it and wondered how a woman (or eventually women) might feel if they were able to navigate a seat at this table. With COVID-19 requiring a greater reliance on Zoom for meetings it is unclear whether this has resulted in inequalities becoming further entrenched as fewer new people are inducted into governance or has access to meetings from home opened up space for women's participation? 


\section{In place: farm women make place matter}

I often wonder "how do those bodies absented from place leave their mark?"

As the Water Trust example shows, especially for rural and farming women, their impact is sometimes erased; while strong in the fabric of history, their mark is often grainy like the layered and discernible strands of stringy bark on the trunk of a gumtree.

Having spoken to farming and rural women over the courses of many research projects I have many memories of the hard, often undervalued, work women undertake on- and off-farm (Bryant and Pini, 2011). An interview with Sophie stays with me as her work is often unacknowledged as farm labor in official statistics but her presence provides the rhythm for ongoing production. I came to Sophie's farm to interview her about her experiences of being pluriactive (farming and working offfarm) and recall:

The house was new but not. The floors were concrete and the walls plastered but unpainted. There were big windows in the living room facing the long stretches of paddocks where you could see stumpy growth - cabbages I think. Sophie explained how she had been on night shift packing fruit and veg for a corporate farm. She said she took the night shift so she could be home to get the kids to school then collect them after school. But she also needed to work on-farm especially during harvest. There was only so much they could pay out for farm workers. For Sophie the unpainted walls and lack of soft furnishings were too much to think about. She told me "you know I just don't care about ..." [waving her hand around the room]. I looked into her eyes and I could read her exhaustion.

In Australia due to COVID-19, farming women are undertaking more labor. In horticulture, for example, women's hours on-farm have become longer as temporary visas for overseas farm workers have been halted, and during snap lockdowns women with school-aged children are doing more domestic work and home schooling. However, the pandemic has come at a time when other disasters are impacting rural Australia - a recent prolonged drought, devasting bushfires and severe floods, as well as the financial consequences of international trade disputes. What is yet to be known is how climatic disaster, COVID-19, and the political economy have impacted on farming women's socio-economic activities and overall health. Research in place is now necessary to feel and sense the textures of altered landscapes and altered lives. 


\section{Lia Bryant}

\section{In place and out of place: missing the textures of gender politics}

By entering the rural as a researcher residing in a city, I have had the opportunity to grapple with the textures of gender politics in place alongside my own gender politics. My memory below reveals body politics in place or the gendering of space in the act of becoming:

She had to go to Mudamuckla. There were no maps and she relied on directions taken from a telephone call. She drove the government car down dirt roads where no buildings or humans were in sight. In the vastness she felt vulnerable and uncertain. Too much space. She saw a shed - could this be the landmark where she was told she must turn right? Again isolation and uncertainty. Deciding to turn right she drove down a narrow dirt path seemingly leading nowhere. Go on or turn back? Well she did go on and found herself in a paddock surrounded by cows. She waved her arms furiously upward trying to catch the male farmer's attention. He smiled at her ... [foolishness] and gave her yet more directions. Arriving at her destination the reliable government sedan seemed to be swerving - Oh God, she thought, I have a flat tyre. Anxiety rose. She attempted to fight back feelings of inadequacy. She must now interview a woman a similar age to herself who works on the local council, runs a farm and has a child. The interview proceeds and the woman generously tells her story. In this space, the woman's home, she feels awkward but must present as knowledgeable and confident. She feels the difference in their lives, not simply difference about urban or rural lifestyle, but also difference around privilege. She is paid well and lives in a home, the woman lives in a shed. One room is where the family eats and sleeps. There is no bathroom in sight. The time came to leave. How to tell the women the tyre is flat and she can't change it? She feebly says, "I am not used to this type of car and can't change the tyre." The woman hands her the screaming child. She holds it at arm's length not knowing how to quieten it, not knowing how to hold it. The woman proceeds to change the tyre and pacify the child. She feels inadequate as a woman. (Bryant and Livholts, 2007:34-35) (Figure 14.3)

In the memory above, I recall feelings of vulnerability and the vastness of the countryside. I feel my body diminished and exposed. I feel "out of place" and stripped of competence (Bryant and Livholts, 2015:169). I am being forced to acknowledge my gendered and classed academic body and the gendered norms that I am unable to fulfil. 


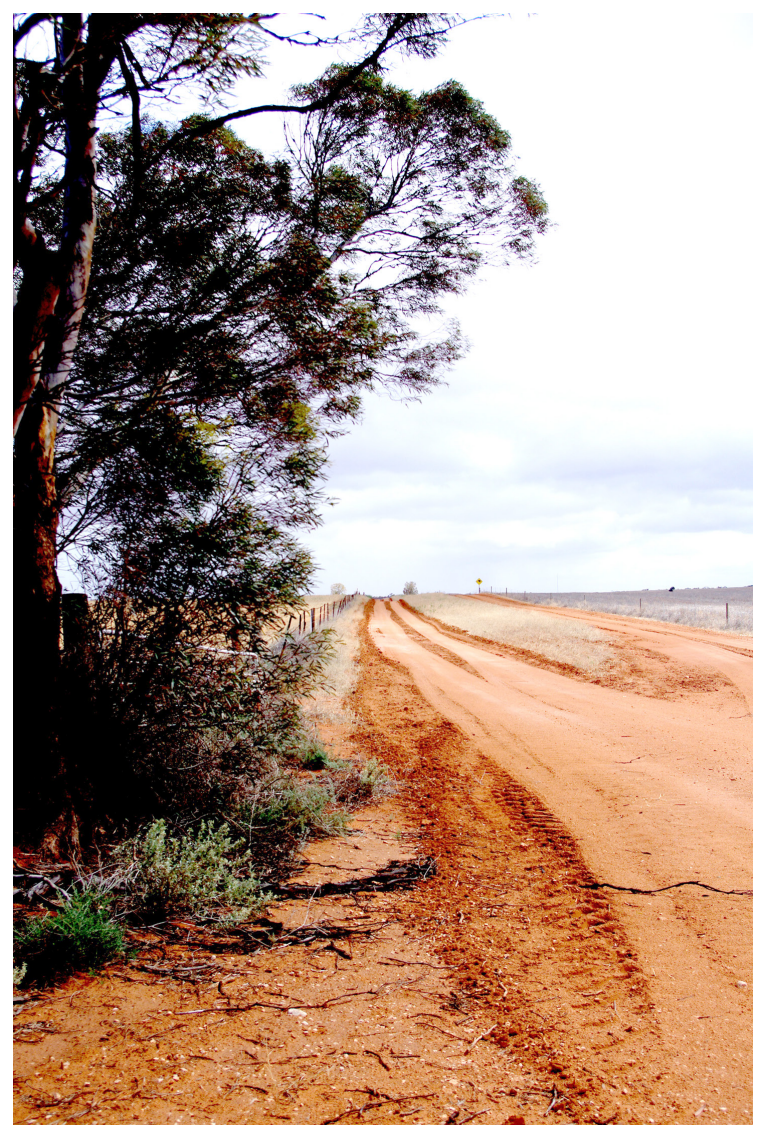

Figure 14.3 Driveway (Lia Bryant).

Being "in place" in this memory brings forth how we see rural places from our situated knowledges (Haraway, 1998). For me, being in place is a reflexive confrontation with my situated knowledge as a feminist academic shaped by multiple discourses and practices of gender (Bryant and Pini, 2011:142). Moral judgments also come into place. While these may come to the fore over the phone, in this instant it is the experience of the visuality of place, the moral middle-class judgment of where the woman lives and the sensory and embodied response to how to quieten a crying baby (Bryant and Livholts, 2015). What I understood through abstract knowledge became an experiential lesson - my moral judgments shaped my emotional, cognitive, and sensory responses to feeling out of place. 


\section{Lia Bryant}

Looking back at this memory of myself as a younger woman in my 20 s, I also learn that the embodied gaze of the woman I interviewed is missing. I wonder what her experience of my visiting was like? Did I disrupt, reinforce, or in any way shape her sense of place and gender? For me this story highlights the subtleties of place and the nuanced interactions that occur in place that for a rural researcher cannot be simply replaced by technologies during the pandemic.

\section{In and put of place: virtual access}

Here I am, 32 years later, at a time most of us could not have imagined. As a rural researcher, I have taken for granted that I can get into a car and a few hours later be in the country. I have taken for granted that I have access to being in place to experience and be challenged. Simply put, to feel place. It is important to me to shape my praxis through attempting to understand the people I research with, the communities I collaborate with and, in and out of this context, to attempt to understand myself. Recently, I had a telephone interview with a male farmer about co-designing resources for the prevention of male farmer suicide. I have been working on this topic for some years and I advocate for a place-based approach to tailoring suicide prevention that is community driven and state supported. I now need to undertake this research by phone. Hence, place in this context is restricted to voice, however, like face-to-face interactions, the farmer's expertise of distress, stories of assistance, and recovery in place are at the centre of the research which reinforce a place-based understanding.

I have always liked the rhythm and the nonsensical feeling to the word discombobulate. In the first instance, telephone-based research discombobulates me. At the time, I write:

She got the time wrong. Of course there is a time difference across the states in Australia. She knows this. She rings people all the time in other states. But today she rings at the appointed $1 \mathrm{pm} .1 \mathrm{pm}$ in New South Wales not her home town. She receives an email, "hey Lia did we get mixed up with our time zones? ... I am available at 4 if you can ring." The farmer is so gracious.

Time is disrupted through the virtual, especially crossing time zones. But as I have been arguing, so are other things. I learn from the virtual some important lessons. The first, and most obvious - check the time in places other than your own! Secondly, a telephone interview requires me to listen differently. I am transfixed, I hold the phone tight as though this might bring me closer to where he is. I only have the voice in which to determine how he is feeling, 
how interested he is in the topic, how to build a relationship with him and put him at ease. I have to think about how I would hear gendered cues, how I would hear if a farming man is comfortable talking to me about male farmer suicide. Thirdly, and most importantly, will the phone make this easier or harder for him to communicate his emotions, experiences, and ideas?

Sarah Ahmed's (2004) argument that voices suppress and express emotions reshapes the way I hear. I attempt to determine what is being suppressed as well as expressed. I hear the pauses in how he speaks. The pauses I feel deep in my body. I think he pauses to garner space, to tentatively consider what is to be said next and how to express his emotions.

Literature focused on the telephone suggests that one of the first questions people ask when calling mobile phones is "Where are you?" (GarciaMontes et al., 2006). It is interesting how we wish to place people. However, a phone conversation is anything but "unlocated" and people may be in multiple spaces within place as conversations unfold. As Bryant and Livholts (2013:12) suggest:

when receiving and making telephone calls in the home it cannot be assumed that the individual is in one physical space during the course of the conversation ... nor can it be assumed that there is one cognitive space as there is the possibility that the person is distracted, multitasking or indeed even having more than one conversation at the same time.

Despite COVID-19 restricting public movements, it is movements that happen in private spaces during moments of a telephone interview that cannot really be known. Face-to-face (and Zoom) interviews, more often than not, fix people in place. During this time of restriction, perhaps there is more to be known about how farming women and men move through private spaces and how this may shape how they narrate their lives and express emotions during telephone interviews.

\section{In conclusion}

I am suggesting a sensory engagement with place provides a stream of memories. It also enables a reflexive engagement with places and spaces which enables rural researchers to learn about the texture and complexity of how gendering occurs in time and place. It provides us with a location in which to examine how farmers negotiate social relations and our situatedness that disrupts time and place as we enter the rural. COVID restrictions alter our reflexive learning about place. 


\section{Lia Bryant}

For now, I think of the yellow fields of wheat and wonder how long it will be until I see them flickering past once again. I look out the window of my own home. Paved garden, trimmed roses. While I am away from the rural by necessity, I try hard to remain engaged virtually with both places and people.

\section{References}

Ahmed, S. (2004) Declarations of Whiteness: The Non-performativity of Antiracism, Borderlands e-journal, 3, 2. Available from: http://www.borderlands.net.au/ vol3no2_2004/ahmed_declarations.htm

Barad, K. (2003) Posthumanist Performativity: Toward an Understanding of How Matter Comes to Matter, Signs: Journal of Women in Culture and Society, 28, 3, 801-831.

Bryant, L. and George, J. (2016) Water and Rural Communities. Oxon: Routledge.

Bryant, L. and Livholts, M. (2007) Exploring the Gendering of Space by Using Memory Work as a Reflexive Research Method, International Journal of Qualitative Methods, 6, 29-43.

Bryant, L. and Livholts, M. (2013) Location and Unlocation: Examining Gender and Telephony Through Autoethnographic Textual and Visual Methods, International Journal of Qualitative Methods, 12, 1, 403-419.

Bryant, L. and Livholts, M. (2015) Memory Work and Reflexive Gendered Bodies: Examining Rural Landscapes in the Making, in eds Pini, B., Brandth, B. and Little, J., Rural Feminisms, Lanham: Lexington Books, 181-194.

Bryant, L. and Pini, B. (2011) Gender and Rurality, NY and UK, Routledge.

Butler, J. (1993) Bodies that Matter: On the Discursive Limits of "Sex". New York: Routledge.

Garcia-Montes, J.M., Caballero-Munõ, S.D. and Pérez-Álvarez, M. (2006) Changes in the Self Resulting from the Use of Mobile Phones, Media, Culture \& Society, $28,1,67-82$.

Haraway, D. (1988) Situated Knowledges: The Science Question in Feminism and the Privilege of Partial Perspective, Feminist Studies, 14, 3, 575-599.

Haraway, D.J. (2008) When Species Meet. Minneapolis: University of Minnesota Press.

Jacobs, M. (2006) A Geography of Big Things, Cultural Geographies, 13, 1, 1-27.

Stewart, K. (2011) Atmospheric Attunements, Environment and Planning D: Society and Space, 29, 445-453.

Tolia-Kelly, D.P. (2011) The Geographies of Cultural Geography III: Material Geographies, Vibrant Matters and Risking Surface Geographies, Progress in Human Geography, 37, 1, 153-160. 